By CHARLES W. DAVID

\title{
Report from Europe
}

Dr. David is director, University of Pennsylvania Libraries.

I AST YEAR under the heading of "Report L on Europe" we had a highly informative discourse ${ }^{2}$ by a member of the Library of Congress mission. Today we probably have no one among us as qualified as Reuben Peiss was to make such a report, nor would it seem to be called for since the year has seen strides of progress in the resumption of commercial relations with Europe.

"True cooperation" in the field of librarianship and documentation at the international level, which is considered in this paper, is a very large subject. Any qualifications that I have to speak on this subject stem from my recent attendance at the two conferences of the International Federation of Documentation. It will not be a full statement on Europe, but rather a report on a small part of the international program in which I had some part.

For almost fifty years there has been in existence an organization which is now known as the International Federation of Documentation (F.I.D.). It has had a somewhat checkered career. During the war there was difficulty to keep it alive, but it did survive, thanks to the courage and persistence especially of groups in Switzerland and Holland. Since the war it has risen like a Phoenix from the ashes and sprung into new life. It now seems to be marching forward into a new era of usefulness.

1 Paper presented at the Conference of Eastern College Librarians, Columbia University, Nov. 29, 1947. ${ }_{2}$ College and Research Libraries 8: ir 3-19, April 1947.
There is one feature of the postwar epoch which seems to make a particular reason for the current revival of F.I.D. That is the birth of UNESCO, the United Nations Educational, Scientific, and Cultural Organization, which has been created in the hope of bringing about better international relations by working with the thoughts of men, and their expression and dissemination throughout the world. Most of you are in some degree familiar with the ambitious program which has been developed for UNESCO, and you know that very considerable parts of that program fall in the realm of librarianship and documentation. Now in general UNESCO, starting from scratch and with a complex organization to create and personnel to assemble before it can become an effective influence, has no desire to become an operating agency or to set up operating agencies of its own so long as it can make use of existing agencies which by reason of their fields of interest, experience, and personnel are in a position to act for it and serve its purposes. In brief, UNESCO desires most of all to be an overall planning and coordinating body in the several fields of its interests rather than to undertake operations of its own in those fields, provided it can get its plans carried out by already existing agencies.

It is for this reason that UNESCO has been greatly interested in F.I.D., in I.F.L.A. (International Federation of Library Associations), and in I.S.O. (International Organization for Standardization). Hence, there has been a peculiar inspiration, not to say stimulation, for these organizations to spring into active life 
under the favoring influence of UNESCO.

Let me speak more particularly about F.I.D., in the affairs of which I have had some part. With a spirit and energy truly amazing, it has held two international conferences, one in Paris in bleak November 1946, and the other in Bern last August in a week of glorious weather. Both conferences were remarkably well attended. At the last, there was an attendance of more than 200, and representation of 18 countries and also of the United Nations, UNESCO, the International Organization for Standardization, and the International Federation of Library Associations. Considerable lists of learned papers (since published) were presented at both meetings.

\section{Major Problems}

But let me speak not of the papers but of the major problems which were before the council of F.I.D. If the revived federation were to play successfully the role for which it appeared to be cast, it was manifestly necessary to strengthen its organization, revise its constitution, and increase its resources. Much attention has accordingly been given to these matters.

A radically revised constitution appears about to be adopted. Its main features call for F.I.D. to be made up primarily of a group of "national committees," one from each member country, to which certain international members may be added; for its affairs to be controlled essentially by a council which is representative of the members, but for a smaller committee of action to act at need on behalf of the council between meetings. There is a permanent secretariat at The Hague. The general secretary is F. Donker Duyvis of the Dutch Patent Office. The president is Charles LeMaistre of London, who is also the general secretary of I.S.O.

The financial resources of F.I.D. have in the past been very limited, the contributions of members being surprisingly small, and the organization has been largely supported by the Dutch national member with some private help and perhaps a certain amount of silent help from the Dutch Patent Office. However, it is now clear that F.I.D. cannot continue on such an informal and insecure financial footing; and, therefore, a revised scale of dues has been adopted which, if all members will pay and if the membership can be successfully extended, will result in a very considerable annual income which in turn will make a more effective secretariat possible. There is also ground to hope that in the near future moderate financial assistance may be obtained from UNESCO-indeed word has come within the last few days from Mexico City which would seem to indicate that a UNESCO grant-in-aid for this year is all but assured.

It is also of the utmost importance that the membership be extended. At the moment there are only eleven or twelve national members; and, until this summer, though a considerable number of individual Americans were members, there had never been an American organization holding a national membership. Naturally with an ambitious postwar program in the course of development, there has been a strong desire to have full American participation and to enjoy the strong financial support which it was conceived an American national member would bring. This has been the problem with which I and my fellow delegates, who, in one way or another have represented the American Council of Learned Societies, the American Library Association and its International Relations Board, the Special Libraries Association, and the American Documentation Institute, have been concerned. There has been much discussion as to just what ought to be done, but in the end I was authorized to apply for American membership on behalf of the 
American Documentation Institute, the functions of such American representation to be exercised through an international relations committee of the institute, of which for the time being I am the chairman. In due course I made the application, and I am glad to be able to report that it was received with much enthusiasm and unanimously agreed to.

\section{Expansion of Interests Needed}

What this venture implies is that there must be a considerable expansion of the interests and activity of A.D.I. and perhaps also a considerable reorganization. Certainly there must be found from somewhere considerable added financial resources in order that A.D.I. may support adequately even this single contemplated new activity in the international sphere, and there are many who believe that there are other important new activities which A.D.I. must undertake. These problems are now under consideration.

In the international field what is wanted, once we get an effective organization and adequate financial support for F.I.D., is a precise and definite and approved program which can be carried on effectively by international action. It must be confessed that such a program has not yet been fully formulated. F.I.D. has not yet given sufficient attention to the planning of such a program, and a number of features of it will depend in considerable measure upon discussions which are still continuing with UNESCO. Nevertheless, it is possible to illustrate what such a program is likely to be by listing possible parts of it which are now under consideration, or indeed in some cases have actually been launched.

I. Compilation of an international directory, or guide, to documentation and information services.

2. Compilation of an international guide to document reproduction services.
3. Compilation of a series of small, specialized subject lists of periodicals.

4. Publication of an international quarterly, now known as The Review of Documentation.

5. A new edition of the Index Bibliographicus, formerly issued by the International Institute of Intellectual Cooperation.

6. Study and coordination of abstracting services.

7. Study and standardization of the methods and apparatus of document reproduction.

8. Study and standardization of bibliographical methods.

9. Study and standardization of filing systems.

I0. Standardization of nomenclature and publication of a multilingual vocabulary of librarianship.

II. Study of classification, including an extension of U.D.C. and the establishment of a concordance between it and the Dewey Decimal Classification.

It is already fairly clear, I think, that if action is to be effective there will have to be courageous pruning of the program in order to prevent a dissipation of energies.

The problems of American participation and the program of F.I.D. have diverted me for the moment from the point with which I was concerned, namely the importance of expanding the membership of F.I.D. While great importance was attached to having the United States come in, there was also a strong desire to extend the membership to a number of other countries; and it is known that in some other countries, notably in South Africa and Ireland, efforts are now under way to bring this about. There was a special resolution emphasizing the desirability of bringing in a number of South American countries. It is greatly to be hoped that the national membership will be considerably increased.

I have already referred to two other international organizations with functions somewhat parallel with those of F.I.D., namely I.S.O. (International Organization of Standardization) and I.F.L.A. (Inter- 
national Federation of Library Associations).

As I have already noted, the current president of F.I.D. is also the general secretary of I.S.O. This has made it easy to bring about an understanding between the two organizations for a delimitation of their fields of interest and action. An agreement was formally accepted by F.I.D. at Bern which assigns to F.I.D. sole authority in matters relating to the Universal Decimal Classification but canalizes most matters relating to standardization at the international level through I.S.O., with the provision, however, that F.I.D. and I.F.L.A. shall be represented at such discussions and kept fully informed of decisions.

\section{F.I.D. and I.F.L.A.}

Steps have also been taken to maintain harmonious and cooperative relations between F.I.D. and I.F.L.A. The latter, as most of you doubtless are aware, has been quite as active since the close of the war as has F.I.D. There was a preliminary meeting in Geneva last year. This year in May a much more ambitious congress of the International Committee of I.F.L.A. was held in Oslo. It has been announced that another meeting will be held in this country in 1948, probably in September, though I have learned recently that current economic and exchange difficulties have forced a postponement of that plan. I was not present at the Oslo congress, but I have looked over the proof sheets of its published Actes, and I gain an impression of some fairly close parallels with F.I.D. (and to a lesser degree with I.S.O.). Both organizations are interested in a number of the same things, some joint committees have been set up between them, and many of the same individuals participate in both. Both organizations are cooperating closely with UNESCO. I am sure that many of you have found it difficult to distinguish to your own satisfaction between documentation and librarianship, and therefore the thought will have occurred to you that there may be a certain redundancy in these two international organizations operating in such closely related fields, indeed that a merger between them might be desirable. This thought has certainly occurred to me, as it has to others who have given attention to this matter and whose judgment $I$ respect; and I believe that there is also a feeling among some of the leaders in UNESCO that such a consolidation would be desirable. However, I also sense a certain spirit of rivalry between some librarians and some documentalists which leads me to believe that a merger between these two organizations, desirable though it might be, could hardly be accomplished quickly.

Now I think I have really said my say, but there are some other examples of cooperation at the international level which are of current interest and about which I shall venture to say a few words.

One is the clean-cut piece of work which is now all but accomplished of the American Book Center for War Devastated Libraries, Inc. (A.B.C.), an organization which stems originally, I believe, from the Council of National Library Associations, and has carried on its operations in the Library of Congress. Since its inception, I understand that A.B.C. has gathered in this country and distributed to war-devastated libraries abroad something like 4,000,000 pieces, which are calculated to have amounted in all to about $1,100,000$ volumes. Shipments have gone all told to 33 different countries, although the major portion of them has gone to 13 countries. The project was first designed to run for something like a year, then it was extended to two years, ending in December 1947. Naturally its funds are now running low, and the in-flow of materials for distribution abroad has begun to dry up. Nevertheless, it has not been pos- 
sible to bring the project to an end as promptly as was planned, and its board of directors formally voted to dissolve it as of Mar. 31, I948, "or as soon thereafter as the affairs of the corporation can be liquidated." However, there is strong pressure from various quarters not to let the enterprise end so abruptly. For one thing, there has been created by the fine achievement of A.B.C. a goodwill which it seems a pity to let be dissipated; for another, books continue to flow into the center (and the flow could certainly be stimulated), and the need abroad continues and various organizations like UNESCO, the Commission on International Educational Reconstruction, and the State Department's Office of Voluntary Foreign Aid, are desirous of having the work continued. There is a possibility that additional funds to support the enterprise may be forthcoming early in 1948 , perhaps from the organization known as American Overseas Aid. And finally, even though the work of A.B.C. in its present form should come to an end in the relatively near future, there is the possibility that it might be converted from a one-way to a two-way enterprise and continued as an agency for international exchanges.

\section{Successor Agency to A.B.C.}

The decision to dissolve the center on Mar. 3I, 1948, therefore, was so worded as to clear the way for the formation of a more permanent successor agency which would take over its assets and goodwill, carry on its unfinished work, and develop new activities, such as those of an exchange center, which would gradually change its character but perpetuate its usefulness. The first steps toward the formation of such a successor agency have already been taken, and it may confidently be expected that as A.B.C. in its present form dissolves the new organization will be in readiness to take over.
Another subject about which I ought to speak briefly is the Cooperative Acquisition of Recent Foreign Publications Project of the Library of Congress which has saved from destruction and brought to our collections many hundreds of thousands of volumes. On the side of procurement in Europe you had the full report on this project by Mr. Peiss a year ago. Before that and since, many of us who have responsibility for research libraries have had abundant experience on the receiving end. The experience has not always been to our entire satisfaction because, to speak very candidly among friends, we have inevitably received a good many items which we did not want, and we tend to give our attention to these while we remain unconscious of the great number of very valuable items which have been received at small cost and which, in a good many cases, we should have been hardly able to attain through our individual efforts. When the enterprise is viewed as a whole, in spite of these imperfections, it stands forth as an admirable example of cooperation and library statesmanship. According to the latest word, it is now anticipated that the project will be completed by June 30 next year, and possibly even by April 30.

Another enterprise which I should mention is the Princeton Conference on International Exchanges which was held in November 1946. The conference ended with the drafting of two dozen far-reaching resolutions, many of them involving cooperation at the international level. As usually happens with resolutions, it has not been easy to implement them in such a way as to make them effective ; and their implications are so broad that a precise report on them is difficult. But I may note that the proposal which I have discussed to convert A.B.C. into an international exchange center grows directly out of them. So also does a recent achievement of the Associa- 
tion of Research Libraries in gaining important relief for importing libraries from customs barriers and costs. Several of the Princeton resolutions are now under study by appropriate committees, notably committees of the A.R.L.

Perhaps the most conspicuous example of cooperation at the international level is the Farmington Plan, which is the principal enterprise now before the Association of Research Libraries and is intended when fully developed to bring into this country and centrally record, at least one copy of every foreign publication of probable research value. Though the Farmington Plan is older than the Princeton resolutions, it figures prominently among them. The Association of Research Libraries is currently at grips with it. Matters have been in something of a crisis since the meeting in San Francisco last summer; but we got back on the track at a meeting here on the Columbia campus, Nov. 28, 1947. So the decision still stands to put the plan into effect experimentally for 1948 imprints, to be obtained from three foreign countries, namely Sweden, Switzerland, and France.

\section{Overlapping in Abstracting Field}

Finally, let me say something about a significant effort on the part of UNESCO in the field of abstracting (this also gets mentioned in one of the Princeton resolutions). There has been much concern because of overlapping and competition between four abstracting services which are now operating in the biological and medical fields, namely, Biological Abstracts, British Abstracts, World Abstracts of Medical Sciences, and Excerpta Medica. Accordingly, on the initiative of the Natural Sciences Section of UNESCO, a conference was called in Paris early last October of representatives of these four services, of the American Medical Association, of the
World Health Organization, and of F.I.D. with a view to bringing about orderly coverage of the fields in question, with close cooperation substituted for competition, with the elimination of unnecessary duplication, and with a reduction of expense to subscribers. Naturally the conferees were not in a position to make binding agreements on the spot; but it can, I think, be said that very real progress was made. For one thing it became clear that such cooperative agreements are only practicable among nonprofit organizations, and I understand that Excerpta Medica is now in process of being transformed into such an organization. For another thing it appeared clear that important cooperative agreements of the kind that have been suggested are practical and probably will be concluded in due course. The conference achieved a sufficient preliminary success to encourage UNESCO to consider the calling, possibly late next year, of a much larger conference to deal with the abstracting problem on a broader scale; and in the meantime it was decided to set up an interim committee of the interests which were represented at the Paris conference to work for a realization of the proposed agreements on cooperation among the four services and to prepare the way for the larger conference.

I have now run through the list of cooperative efforts in the field of librarianship and documentation at the international level about which I have some knowledge. My general conclusion is that while progress will probably appear to you to be slow, that a discouraging amount of time and effort are being consumed in preliminaries, still on the whole the prospect is an encouraging one. There have already been some concrete accomplishments, and there is fair hope of much greater achievements in the not too distant future. We must build on what has already been done. 